\title{
An Assessment of Policies that Support Having Children from the Perspectives of Equity, Efficiency and Efficacy
}

\author{
Peter McDonald ${ }^{*}$
}

\begin{abstract}
In a context where 46 countries now consider their fertility rate to be too low, attention is turning to the need for policy actions to increase fertility rates. This article discusses the reasons why action is required and why countries have been slow to take policy action. It then considers a wide range of possible policies and assesses them against a set of eleven social policy principles. The policies examined include tax-transfer policies, subsidised services, childcare and early childhood education, parent leave and working hours policies, employment policies for young people, public education campaigns and broader social arrangements. The conclusion drawn is that the focus of policy should not be pronatalism as such but support for families with children. Support for families with children means good family policy, good gender policy, good employment/human capital policy, good child development policy and, if there is a need to increase or sustain birth rates, it will also mean good birth policy.
\end{abstract}

\section{Introduction: the Need for Policies that Support those who have Children}

Fertility rates have fallen to low levels that are without precedent especially in many countries in continental Europe and East Asia. Survey evidence in most of these countries indicates that young people are having fewer children than they want to have (van Peer 2002; d'Addio and d'Ercole 2005). I have argued recently that this situation is a result of new uncertainties in the lives of young people

\footnotetext{
Demography \& Sociology Program, Research School of Social Sciences, The Australian National University, Canberra ACT 0200, Australia.

Email: peter.mcdonald@anu.edu.au
} 
arising from economic deregulation and social liberalisation in the past few decades (McDonald 2006). Because of gender inequity, the new uncertainties or risks are greater for women than for men, although both are affected. While the desire for the intimacy provided by family relationships remains very strong, it is easier to deal with the personal and economic risks of modern society if others are not affected by the outcome. Governments have played a leading role in the social and economic changes that have brought pressure to bear on all forms of altruistic behaviour but, most especially, upon family life. Because of this, it is incumbent upon governments to restore the balance through family support programs. This is the micro-level argument in favour of 'pronatalist' policy.

At the macro-level, sustained low fertility rates have a devastating impact on future labour supply at the same time as the number of older people is increasing dramatically. If recent demographic trends were to continue, by 2040, the labour force in Japan would fall by 20 million workers and by 11 million workers in both Italy and Germany (McDonald and Kippen 2001). These losses are entirely losses of younger workers and in an era of rapidly changing technology, economies that are blasé about their future supply of young technologically skilled workers are taking a considerable risk (McDonald and Temple 2006; Skirbekk 2004). Using several economic indicators, Ogawa et al. (2005) demonstrate that, in Japan, the demographic bonus conferred by the earlier decline in fertility was transformed to a 'demographic onus' from 2000 onwards due to the impacts on the age structure of sustained low fertility. In Europe as well, this message is receiving more prominence as very low fertility rates persist for longer periods and as ageing societies face the certain knowledge that their social insurance systems are not viable in a future with a much older population and a sharply reduced labour supply (Commission of the European Communities 2005).

Thus, it is prudent for countries to try to avoid fertility rates that are below an average of 1.5 births per woman through policy regimes that support having children. While societies do not necessarily have to aim to achieve replacement level fertility, there is a 'safety zone' for below replacement fertility that has a lower limit above 1.5 births per women. In this safety zone, the effects of low fertility on future labour supply can be offset by migration or, alternatively, future labour supplies can be allowed to fall at a slow and controlled rate. Countries with fertility rates below 1.5 births per woman need to examine the policy directions that would lift their fertility into the safety zone.

The relevant fertility rate for policy is the cross-sectional fertility rate because it is this rate that determines the number of births occurring in any given year and hence determines the age structure of the population. To wait for a homeostatic correction to low fertility or to wait for the effects of changes in the tempo of childbearing to work themselves out is risky (McDonald 2006). The muchawaited correction may never come and, even if it does come eventually, the damage to age structure may already have been done. 


\section{Policy Effectiveness}

There is considerable evidence that policy can be effective in increasing birth rates. At the broadest level, there is a cultural divide between those countries that have very low fertility rates (under 1.5 births per woman: all the southern European countries, all the German-speaking European countries and all the advanced East Asian countries) and countries where fertility is only moderately low (all the Nordic countries, all the French and Dutch-speaking European countries and all the English-speaking countries). The group of countries with fertility rates under 1.5 tend to be countries where there is a separation between family and state; families are expected to support their own. Accordingly, these countries have been slow to introduce family support policies. In the group with only moderately low fertility, governments have a long history of providing support to families. At the more specific level, research studies have shown that cash payments, child care and family-friendly workplace arrangements have supported the birth rate in numerous instances (McDonald 2006).

Policies must not only be broadly effective, there must also be a political acceptance that public resources should be directed towards pronatalist policy. Among policy makers, there is increasing recognition of the effects of very low fertility rates as described in the previous section, hence, it is not difficult to convince them that there is a problem. What is more difficult is to sell the message to the general public that the root cause is sustained low fertility and to devise policies that will have broad political acceptance.

In relation to the political acceptance of pronatalist policy, very low fertility is often seen as the cumulated outcome of individuals acting in their own interest. Accordingly policy would take the form described by Demeny (2003) based on an essay published in 1833 by William Foster Lloyd:

Population policy should therefore strive towards institutions and incentive systems - a constitution of society - that provides signals to individuals guiding them to behave in harmony with the collective interest (p. 754).

However, based on survey evidence that many people in advanced countries fail to achieve the number of children that they would prefer to have, I have argued that there is a need to strive for institutions and support systems - a constitution of society - enabling people to have the number of children that they already want to have. It is not that people have to be convinced to have children but rather that society needs to be structured in ways that enable them to do so. If this is indeed the case as I have argued (McDonald 2006), it provides a strong ideological basis for the formulation of policies that support births. Such policies can be argued on the basis that they not only deal with issues of future labour supply (the common future good), but they also improve the well-being of individuals here and now by allowing them to fulfil their desire for children. The 
latter is a stronger foundation for broad-based political support because it can be argued, as is frequently done in the Nordic countries, that promotion of births is a side effect of policies legitimately designed for the achievement of other desirable social or economic objectives, essentially family support policy.

Despite the cogency of this 'side effect' approach, I still believe that the importance of policy to support births should be conveyed to the public rather than being hidden away. If this can be done in an appropriate way, the argument for reform of social and economic institutions becomes much more powerful. While there is an element of fiscal risk that pronatalist policies may not work, the future fiscal risk of doing nothing in countries with very low fertility rates is far greater.

In the following sections, I discuss the obstacles to policies to support the birth rate and then move to a discussion of the principles upon which effective policies need to be based. This is followed by an assessment of potential policies in relation to these principles.

\section{Obstacles to Policies to Promote Births}

Pronatalism is here defined as government policy aimed at increasing a nation's birth rate. There has been an apparent reluctance on the part of many governments to adopt explicit pronatalist policies, although this reluctance is beginning to fade. The number of OECD countries that reported to the United Nations that they had policies in place to maintain or raise the fertility level remained at seven from 1976 to 1996 . However, the number had risen to 13 by 2003 and more countries have announced pronatalist policies since 2003 (d'Addio and d'Ercole 2005: 47). Most notably, Russian President Vladimir Putin has announced new policies related to increasing the birth rate in his 2006 State of the Nation address (PDR 2006). The historical reluctance of governments to adopt pronatalist polices has many origins as discussed below.

In relatively recent history, pronatalism was associated with fascist or totalitarian regimes. Societies that have removed themselves from these influences, often with great pain, are very loath to revisit the past (Lutz et al. 2003). As a consequence, even the public discussion of the long-term effects of low fertility rates is stifled. Also, it is near to impossible in liberal states to get new policy directions on the political agenda without prior public discussion.

Pronatalism has also been associated with eugenicism, the philosophy that it is incumbent upon societies to improve the quality of their population through selective breeding (Mazumdar 2003; Teitelbaum and Winter 1985, ch.3). Inevitably, if some form of universal pronatalist incentive is instigated, it will be denigrated on the basis that 'the wrong people will have children'. The wrong people here are the poor, teenagers and, in some instances, certain ethnic or racial groups. The introduction of a large universal maternity payment in Australia in 
2004 provoked such responses (Editorial, The Australian, 11 May 2004). On the other hand, if pronatalist incentives are directed only to the 'preferred' people as has tended to be the case in Singapore (the rich, the educated, those of the preferred ethnicity), pronatalism can be portrayed as being inequitable or racist. At a broader level, in a world that has been so focussed upon achieving control over rapid population growth through antinatalist policy in poor countries, pronatalism in rich countries appears to be, at best, inconsistent and, at worst, racist. Poorer countries may react to a situation where wealthy countries are seen as promoting family planning in poor countries while promoting more births in their own countries. Indeed, pronatalism in wealthy countries has been seen as undermining international efforts for the reduction of fertility in those countries that still have high fertility. While no longer the case, in general, UN agencies were slow to recognise very low fertility as a population issue because they were concerned about impacts upon their fertility reduction efforts.

As Demeny (2003) has observed, modern populations are much more sanguine about the prospect of population decline than was the case even 30 years ago. Awareness of the impact of humankind upon the natural environment at both the global and the local scales is now very powerful. Why would we want more births when each additional human contributes to greenhouse gas emissions, consumption of scarce resources and to local pollution and overcrowding? There is a very sound demographic-economic response to this question (McDonald and Kippen 1999, 2001), but the environmental arguments are powerful.

To the extent that pronatalism is presented as the need for women to do their duty for the nation, pronatalism is anti-feminist. Pronatalism in this context is portrayed both by proponents and opponents as the bulwark of 'traditional family values' by which women will return to the role preordained for them by nature and by God. While appealing to a minority of conservatives that already see themselves as fulfilling their national duty, overall, such a policy approach is more likely to be counter-productive leading to even lower fertility.

Pronatalism can also be seen as an invasion of the rights or the privacy of individuals to determine freely the number of children they want to have. The objection is raised that 'the government has no place in the bedroom'.

Pronatalism necessarily implies a transfer of financial resources or social benefits from those who do not have children to those who do have children. Those opposed to family support policies on this ground argue that, because the decision to have a child is a private choice, those who make this decision should bear the costs and consequences of their own decision.

If there is a problem of too few births, it is a problem of future labour shortage. Surely this problem can be solved more efficiently and more humanely through international migration? This objection can and has been answered by straightforward demographic modelling (United Nations 2000) but the objection has popular appeal in 'left-wing' segments of the population particularly where pronatalism is or is seen to be part of a right-wing agenda. 
Finally, there is the objection that policies to promote births simply do not work and therefore they are a waste of scarce national fiscal resources that would be better employed in new productive investment or in education of the children that the nation already has.

In total, these are a very powerful set of objections to any government that embarks upon a policy program to promote the nation's birth rate. They are powerful not least of all because they are felt in different form and in different degree across the spectrums of society, from liberal to conservative, from rich to poor. Each objection has its own specific response but, in the end, pronatalism will be ineffective unless a strong and cogent case is presented as to why policies to support the birth rate are required at all.

\section{The Various Faces of Policy to Promote Births}

Policy to promote births can come in the form of policies related to the taxtransfer system, intergenerational transfers, employment, housing, gender equity, organisation of the workplace, education and human capital formation, family and children's services, community development and child development policy. We seek policies in these domains that reform institutions and provide incentives (or remove disincentives) in ways that support childbearing and childrearing while at the same time achieving desirable goals within the particular domain. Many examples are presented below in the discussion of specific policy initiatives. The spread of potential pronatalist policies across a wide array of policy domains also gives rise to the potential for incremental reform, that is, elements of a package of reforms can be addressed in sequence rather than simultaneously. For fiscal and political reasons, grand reform is almost never an option. Incrementalism is inevitable.

The many faces of birth promotion policy imply that such policies involve institutional changes that are beneficial to the well-being of individual families with children. This is an advantage in that it can be argued that a chosen policy regime has a double benefit. The message of a double benefit (to individual families and to the nation) has been important in bringing down fertility in developing countries. It is even more important in raising fertility from very low levels.

\section{Principles of policy to support the birth rate}

Before considering specific policies, consideration needs to be given to the principles upon which family support policy should be based in ideal circumstances. 


\subsection{The Social Value of Children}

The underlying rationale for government involvement in support of families is recognition of the social value of children. Fundamentally, children are tomorrow's citizens and tomorrow's workers. This is the economic value of children to society but many also assert that becoming a parent is a right that should be protected in all societies and accordingly, social institutions should be organised in such a way that this right can be exercised without excessive penalty. As this argument applies to all parents irrespective of their circumstances, it implies that the principle of horizontal equity should apply to family support policy. Horizontal equity means that society recognises the additional costs faced by those raising children compared to those not raising children irrespective of income level and compensates for this additional cost at least in part. This can take the form of cash payments for children, tax rebates or deductions related to the care of children or their costs, or subsidised children's services. It is inevitable given public fiscal constraints that most of the cost of children will be borne by parents. Societal transfers to those who have children are a partial offset to parents for the costs of providing a social benefit.

\subsection{Neutrality in Relation to the Working Circumstances of Parents}

So that the labour market operates efficiently, couples with children need to be able to change their working hours without incurring major penalty. For example, a financial benefit that is contingent upon the mother not being in paid employment will operate as a work disincentive when she wants to return to work. A mother who returns to work after some time at home, like all other workers, also incurs substantial costs of working such as transport, clothing, equipment and additional household expenses, and also incurs child care costs. These losses do not have a neutral effect on behaviour, that is, they prevent people making the choices that are best for themselves and for their children. They fail the efficiency principle at the micro level. Where the disincentives lead to withdrawal from employment or to a slower return to employment, the country's human capital, expensively produced, is underutilised, government tax revenue is reduced and employers may face skill shortages. This is inefficiency at the macro level. To ensure that policies are neutral in regard to the work circumstances of the parents, they should be designed as entitlements attached to the child and not be added or taken away as either parent changes his or her level of work force participation. 


\subsection{Gender Neutrality}

While it is overwhelmingly the case in all countries that mothers rather than fathers take time out of the work force to care for children, a gender-neutral system of benefits means that the rules apply equally in cases where the reverse is true. As it becomes more common that the earning potential of the mother exceeds the earning potential of the father and as new generations take a more enlightened approach to gender equity, more couples are likely to prefer arrangements that involve father-care. A gender-neutral system facilitates this choice. Paid maternity leave is not gender-neutral, but, in this instance, for a period of around three months after birth, there is a health argument that justifies discrimination.

\subsection{Workplace Benefits: by Negotiation or Legislation?}

The starting point for employers is that they should have the right to negotiate employment conditions with their workers in line with competition and profitability in their industry. They are generally opposed if their rights are taken away from them in some way through government legislation. Nevertheless there are indisputable areas such as work safety where employers must comply with government legislation or regulation. Workplace arrangements such as parental leave, family leave, flexible hours of work and access to part-time work are generally seen as being 'family-friendly' and thus potentially a part of policy that is supportive of the birth rate. Thus, the question arises as to whether such workplace arrangements should be legislated (imposed upon employers) or left to negotiation between employers and workers.

For reasons of competition and incentive, employers provide larger benefits to those with the skills that are in demand. Thus, relying solely upon employers and the market will inevitably create social inequities in access to benefits. However, because industrial practices differ very substantially across countries, legislation of family-friendly workplace arrangements inevitably will be highly dependent upon the country concerned, irrespective of principle. Nevertheless, the principle is that workplace benefits that form part of a family support policy should, as far as possible, be provided to workers equally.

\subsection{Child Development Goals should be a Component of Policy Formulation}

Pronatalist policy should not be seen simply as producing bodies for the industrial juggernaut. Such policy should also be seen to be producing human beings who are enlightened, educated citizens. Policy does not end with the birth of the child. Particularly in relation to the provision or subsidisation of non-parental care or education, good child development outcomes should be a component of 
pronatalist policies. This may involve, for example, supporting only high quality child care, not supporting very long child care for infants, providing universal and free early childhood education and quality out-of-school hours care.

\subsection{A Life Course Approach}

A reform agenda should be based on the proposition that families have lifetime strategies based on notions of their likely lifetime income streams. Most young couples expect to have a relatively reduced income stream when they have very young children but they also expect that their income stream will improve again as the children get older and the main carer is able to increase her (almost always, her) participation in the labour force. To do this, she must maintain her human capital or her value to the market place. The accumulation of human capital by both men and women, but especially by women, prior to the birth of the first child has been the driving force behind the delay of first births. Women when they become mothers want to be ensured that, during the period of more intensive care of the child, the family income will be adequate and that, after this period, they will be able to return to the labour force. This implies intensification of government income support in the early years of life of the child. It also means that payments and benefits should not be removed as the level of labour force attachment increases again because this would constitute a work disincentive.

The life cycle approach is also relevant at the population level through intergenerational accounting. In broad terms, societies fund children and, hence, their parents so that the children can become earners who can be taxed to provide support for the next generation of children and for their parents' generation at older ages.

\subsection{Simplicity and Transparency}

It is important that the family support system is simple and transparent. The principle here is that people should know their entitlements, they should have a simple means of obtaining their entitlement and their entitlement should not change with every dollar change in their income, every additional hour that they work, or according to a myriad of other terms or conditions. Achievement of this aim involves a tax transfer and child benefit system that has largely neutral effects as people change their incomes and work force participation. Complexity also involves high administration costs-money that would be better placed in the hands of parents. A transparent system enables parents to determine their entitlements with ease in advance of their decision-making. 


\subsection{The Fiscal Principle}

The Finance Ministry's principle is that any reform must be within the capacity of the country to pay and not a fiscal disaster. We can be certain that, ultimately, this principle will be imposed upon the reformer. Thus, cost must always be in the forefront of consideration.

\subsection{The Efficacy Principle}

Even more obvious, the proposed reform must be efficacious, that is, there should be reason to believe that it will achieve its objectives. As virtually all policies directed at the support of a nation's birth rate have another more direct aim (support to families with children), there is scope for risk taking or acting somewhat experimentally. The policy can be regarded as efficacious if it achieves its more direct aim; if it affects the birth rate, this is a bonus. This also lessens the fiscal risk. Nevertheless, in the end, we are seeking policies that will sustain the birth rate at moderate levels or raise the birth rate from very low levels, that is, policies that work.

\subsection{Political Acceptability}

It is obvious also that any proposed policy must be broadly acceptable in political terms. It is inevitable that governments must engage in public discussion about these issues in order to achieve political acceptance. Only about three per cent of electors will become parents in any year and the percentage is falling as the population ages. Of those who become parents in any year, most would have done so without incentives provided by the government. Thus, any policy designed to modify behaviour in relation to births in any election year will be directly relevant to less than one per cent of electors. The implication from this is that, beyond the immediate beneficiaries, governments must convince a broad range of voters that children have a social benefit that exceeds the social benefit of any alternative use of the same funds.

\subsection{The Policy should be Enduring}

In the end, policy in relation to births is concerned with changing the nature of society such that those who want to have children are able to do so more readily, that is, good birth policy is also good family support policy. If the effects of a policy disappear relatively fast, while the short-term impact may be beneficial, a return to the previous very low fertility circumstance will be undesirable. It may even be counter-productive. Thus, policies need to have an enduring influence. 


\section{Should Policies be Specifically Directed at the Timing of Births?}

Timing is undoubtedly important, however, in general, it is a mistake for policy to attempt to be highly specific about the timing of births. For example, a policy designed to get women to have a child before the age of 27 , besides being difficult to specify or implement, ignores the potential response to policy of all women currently aged 27 years and over. Only those now aged 25-26 years are likely to respond immediately. A broad-based policy, addressed to any woman and her partner who might be considering having a baby or another baby will have a larger cross-sectional effect simply because it will influence many more people at the same time. Nevertheless, policies may vary in the extent to which they affect the timing of births. For example, financial support for the education of children of parity four or more would probably have little impact on the timing of first births. On the other hand, policies that increase the overall sense of security of families may be effective in having young people embark upon family formation at an earlier point.

\section{Tax-transfer Policies}

\subsection{Universal Cash Payment (or Tax Concession) paid at the Birth of a Baby}

From the perspective of a rapid cross-sectional impact on fertility, a large cash transfer or tax rebate that is payable to all parents at the birth of a child is likely to be effective because of its immediacy. Several countries or jurisdictions have adopted this approach in recent years (Norway, Quebec, Italy, Australia). In contrast, any deferred payment, such as tax rebates for the education expenses of children, is likely to be discounted by parents. They will have a sense that they need the money now, not when the baby turns 15 . Such a policy can also be sold as a family support policy because it assists parents with the high costs involved with a baby. Most costs of children studies show that babies cost more than any other age of child up to the time the child reaches the expensive teenage years (McDonald 1990).

In relation to the principles set out above, this policy also scores highly. Because of its directness, it strongly affirms that society values children. Being paid at the same amount in respect of all babies born, it satisfies the horizontal equity criterion. It is neutral in relation to the working circumstances of parentsthere is no loss if either or both parents are working. Being attached to the child's birth, the payment is gender-neutral although there is a question about which parent receives the payment or tax concession. It is a common understanding in 
Australia that cash payments made to the mother are much more likely to be used for the expenses of the child than concessions delivered to the father through the tax system (Howard 2006). In relation to child development, there are strong arguments (breast feeding, bonding, security) that a baby needs to be in the care of its mother in the early months of life. As there are a range of preferences and beliefs in relation to parental care in the early years of life of a child, a universal payment provides parents with choice. For example, the money can be used as income support or as a child care contribution while the mother works. Financial support of this type can also be provided by paid maternity leave, but paid maternity leave may not be universal. It may be paid only to women who have been working for the same employer for a given length of time, it may not be paid to those who are not working, it may be contingent upon a return to work at a time that is not preferred by the parent or the level of payment may be contingent upon prior social insurance accumulation.

There is no policy that is simpler or more transparent than a universal cash payment made to the mother at the birth of a child. Political acceptability of this policy approach is evident at least for the places in which this policy has been introduced in recent years. The introduction of the maternity payment in Australia was preceded by two years of intensive public debate about the relative merits of different policy approaches. The policy received considerable media coverage upon its introduction and while there were some immediate objections that it would encourage 'the wrong people' to have babies as discussed above, these objections faded with time. The government that introduced the policy was reelected with an increased majority at an election held six months after the policy was announced indicating either that the policy was received positively or, at least, that is was not of such importance that people shifted their vote away from the government because of it.

Does such a policy produce more births? In theory, such a payment reduces the price of a child and, as children are not inferior goods, this will necessarily increase demand. The question is: by how much? The answer depends upon the price elasticity and on the size of the payment. In practice, it will be difficult if not impossible to know how much money will produce the desired result. However, the simple nature of this payment makes it very amenable to upward adjustment in relation to the behavioural evidence, that is, experimentation. Also, it must be remembered that in low fertility countries, the aim of a birth policy is only to influence decision making at the margin. At most, a country with very low fertility will be attempting to get about 30 per cent of women to have one child that they would otherwise not have had or a country with moderately low fertility (1.7 and above) will be trying to convince 10 per cent of women now having a child not to change their minds. In general, studies that have been made of this type of payment are unanimous that such payments do have a small marginal effect (Gauthier and Hatzius 1997; Milligan 2002; Adkins 2003). Early data on the Australian initiative indicate that, in the first full quarter in which births could 
have been affected by the new payment (June Quarter 2005), there was an increase of 10 per cent in the number of births compared to the same quarter in the preceding year.

The downside of a universal cash payment at the birth of every baby is the fiscal impact. Marketers would argue that incentives should be targeted only to those in whom they are likely to provoke a change in behaviour. The simple question can be asked: why provide financial incentives to those who would have had the baby in any case? There are several responses to this objection. First, those who are providing a social benefit to society at present should not be disadvantaged for doing so. Second, it is extremely difficult to identify or define the target group, that is, those who will actually change behaviour in response to the incentive. Third, as the policy has another purpose, family support policy, it cannot be targeted. Fourth, targeted payments, by their nature, operate as disincentives if people want to move out of the target group and this is counter to the neutrality principle. Fifth, the astute will learn quickly that they need to appear to be in the target group of the policy. Sixth, a targeted payment has a high likelihood of appearing to be crassly pronatalist. For example, if the payment is only directed to women who are 'high flyers' in terms of education or income because they have low fertility, they are likely to reject the approach as antifeminist and other members of society will resent special privilege being provided to the already privileged. In any case, the social groups that have the lowest fertility rates are likely to have the lowest price elasticity and so the payment would be poorly targeted. Policies targeted to the more highly educated or, more directly, those with higher incomes have been a failure in Singapore.

\subsection{Payments Targeted on Demographic Characteristics}

A payment made in respect of a baby is targeted in the sense that it is based on a demographic characteristic, a child aged zero. Targeting on the basis of demographic characteristics is much less problematic in general than targeting on the basis of social or economic characteristics. Payments could, for example, be targeted to other ages of children. For example, in Australia, I am arguing for higher payments to be made in relation to one- and two-year old children. The logic for these payments is the same as that for the payment for babiesimmediacy, horizontal equity, paid at a time of high need, provides parents with the opportunity to make their own choices in relation to early childhood development and employment.

Probably the most common form of payment related to children is a family allowance or tax concession paid for all dependent children irrespective of their age. Sometimes these payments are higher in respect of older children because of their higher direct cost. This is effective family policy in that it recognises the additional direct costs to families of raising children. As such, family allowances probably have a marginal impact upon fertility although the evidence is not 
strong. The case is made that these allowances have influenced fertility in France where very large tax advantages are available to those with children. On the other hand, this form of concession meets most of the desirable principles: horizontal equity, neutrality in relation to workforce participation and gender, an advantage to child development if the money is spent on the child, simplicity and transparency and political acceptability. The approach also has a life course perspective in that the benefits from government are spread over the lifetime of the child. Beyond cost, the only major disadvantage of family allowances payments is that future benefits will tend to be discounted by those considering a child. Most are concerned with their immediate financial situation. Payments may be based upon the birth order of the child. When it is inevitable that reasonably large proportions of the population will have no children or one child, there is an argument that we need to provide incentives for some people to have three or more children, that is, payments should be targeted at higher-order births. The effectiveness of this approach is doubtful, however, because a very high proportion of children in very low fertility societies are first and second children and incentives should be directed at influencing as many births as possible. Targeting of third and higher-order births is also less likely to have a large crosssectional effect because it would not have much influence upon the age at first birth. Ironically, there may be more political opposition to a policy to influence only third and higher-order births than a policy to influence all births because those opposed to population growth consider large families to be offensive. In Singapore, a tax benefit was provided to mothers who had their first birth before the age of 27. This was a largely unsuccessful attempt to get high-earning women to have their births at an earlier age. The policy was more beneficial to highearning women because the maximum tax concession could only have been obtained by high income earners. As mentioned above, a payment targeted to a narrow age range of mothers will be ineffective because only women currently at that age or slightly below it are likely to respond.

\subsection{Payments Contingent upon the Workforce Status of the Parents}

There are also payments that effectively are directed at 'stay-at-home' mums. Such payments conventionally are tested away rapidly as the second earner's income increases. The theoretical argument in favour of such payments is that, if a mother is supported financially to stay at home with the child, she is more likely to have the child. However, if she is a mother who wishes to work, such payments are inefficient because they operate as a work disincentive. A mother receiving this payment who wishes to return to work will face high effective marginal tax rates. In combination with other increased expenses related to employment, loss of this payment can lock mothers into staying at home. This is anti-feminist, wasteful of the nation's human capital and poor work-family policy. In Australia 
at present, there is a payment of this type that is available, at its extreme, to a woman with one 18 year-old student child irrespective of the income of the woman's partner. The fertility effects of this type of policy are likely to be minimal. It can only be justified, as it has been, on the basis of a conservative view of women's role.

\subsection{Payments Based on Social or Economic Characteristics}

Based on the evidence that women of higher education or higher income are less likely to have children, payments or benefits may be directed towards these women. The political objections to such an approach are very obvious. They can be portrayed as eugenic, anti-feminist and distastefully regressive. Without changes at the workplace such as reduced working hours, these policies almost certainly will not work as evidenced by Singapore's experiments with this type of policy.

\section{Subsidised Services}

Families can be assisted through the provision by government of housing subsidies, education assistance, medical and health services, public transport, and recreation services. Child care services, because of their importance, are discussed in a separate section below. To be pronatalist, those with children have to benefit more from the provision of services than those without children. It can be argued that any benefit available to all people (including children) will benefit households with children more than those without children but this may not be the case if consideration is given to the level of assistance relative to need. In most countries, provision of general medical and health services will be a greater benefit to the aged than to young families. However, forms of health care such as maternal and child health, school medical and dental services and free immunisation benefit only those with children. Obviously, free or subsidised education is directed at those who have children. In relation to housing, first homeowner subsidies may have an effect upon the birth rate as may rental subsidies or priority access to public housing for those who have children.

To the extent that services are conditioned by need, as are most health services, provision should be based upon need and not upon whether or not people have children. Thus, we would expect fertility policy to be directed primarily at universal child-related services such as education or maternal and child health. However, because these services have their own strong direct rationale, their provision may not have a strong or immediate effect upon behaviour in relation to births. In a sense, these are benefits that a society is expected to provide for all children irrespective of the birth rate - thus their use in birth policy would be seen as illegitimate from the political standpoint. The same 
expectation does not necessarily apply to housing subsidies that are not seen generally as being universal entitlements. On the other hand, where there are no supply constraints, housing subsidies can be seen as being inefficient in that they may distort the operation of the market though increased house prices or rents, or through inducement of investment in housing rather than in more productive investment. Assistance with housing may well be very effective, however, in situations where there is a shortage of housing.

In summary, subsidised services, other than child care, are probably relatively inefficient and ineffective instruments in policy directed at increasing the birth rate. However, this conclusion might need to be modified in circumstances where severe housing shortages apply.

\section{Child Care and Early Childhood Education}

Research evidence suggests that the exception in relation to the impact of service provision upon fertility is the provision of child care or child care subsidies. Because child care has not been seen as a universally accepted right in relation to children and parents, its provision becomes associated in the public mind with assisting parents, especially mothers with young children, in combining work and family. The association with fertility is therefore close at hand. It is easily recognised as policy that is designed to support the birth rate as well as supporting women in the workplace. While couples may not calculate ahead to the cost of the tertiary education of their child, they will look ahead a few years at the loss of income that they will have if one parent, usually the mother, is out of the work force for an extended period of time. In this circumstance, the knowledge that affordable, quality child care will be accessible to them when they want to make decisions about work and family is very likely indeed to affect their decision making. The knowledge that child care will be available reduces the perceived risk of having a child and, therefore, is likely to lead to earlier first pregnancies. New provision of child care services across a country would therefore be expected to have a rapid cross-sectional effect upon fertility.

On the other hand, as a service, policy changes with respect to child care are likely to be incremental rather than revolutionary. Responses are sluggish because capital must be found, buildings need to be built, workers have to be trained and employed, quality assurance needs to be defined and policed. Also, child care is more easily provided in some locations than in others. Child care will be more easily provided in child-dense urban suburbs than in remote rural localities. There is also considerable variation in the ways that child care services can be assisted by government. The care may be provided free and universal and be run by the government or it may be entirely provided by the private sector with fee subsidies from government. Fee subsidies may be paid to the provider or to the parent and they may be income-tested. Alternatively, governments may require employers to 
provide child care subsidies or to offer them tax incentives to do so. Governments may subsidise capital costs rather than fees. However, governments cannot legitimately subsidise poor quality care. These many options make child care policy either expensive or messy. Accordingly, in most countries, child care provision, although eminently desirable, tends to fail the simplicity test. It also tends to fail the equity test as it is more available to some than to others because of variations in access caused by location, organisation or cost. Despite this, its impact upon fertility is so fundamental that efforts to overcome these obstacles are crucial.

Child care as early childhood education is seen as being increasingly important to child development especially among children who are deprived in some way. Universal and free early childhood education at least from age three is a direction that would have widespread political support, evident value to child development and, like schools, it would enable parents to more easily combine work and family so long as the hours of education were matched to normal work hours. This policy approach has been introduced in New Zealand and Canada in recent years.

\section{Leave and Working Hours Policies}

As an essential problem related to low fertility is the difficulty of combining work and family, this brings workplaces and employers directly into the equation. As discussed above in relation to principle, the ideal situation is for workplace benefits to be available to all workers equally. Here I refer to such benefits as parental leave paid and unpaid, family leave, freedom from excessively long hours of work, flexible hours of work, access to part-time work and harmonisation of school hours with standard working hours.

Workplace policies are the third leg of the tripod of family support policy that will affect the birth rate, the other two being financial assistance to those with children and child care. Workplace policies are vital, but difficult to implement because of the involvement of a powerful third party, employers. Unlike the general public, it is difficult to convince employers that they should place the interests of the nation ahead of the interests of their company. However, in a competitive labour market, there can be a domino effect as companies, one after the other, provide family-friendly workplace benefits. Those employers that provide such benefits may attract the best workers, and their workers may be more dedicated to the company because it offers these benefits. Competition then induces other companies to do likewise. Governments can set this ball rolling by taking the lead in providing family-friendly benefits to their own workers. This strategy has worked relatively well in Australia where practices introduced into the public sector have filtered into the larger companies. Women in senior personnel positions in private companies have grouped together, across 
companies, to exchange ideas and means by which CEOs can be influenced. This has created a culture within workplaces that is counter to the culture of long work hours and more accepting of regular part-time employment. In a sense, this is private policy implemented beyond government by committed individuals. Where it is difficult for governments to legislate for family-friendly workplace arrangements, this may be the only way to achieve these changes. Inevitably, however, such an approach is discriminatory in that the benefits are only available to public-sector employees or those who work for larger companies. Even within the larger companies, the availability of benefits is usually greater for the upper echelon of workers than for those lower down the structure.

Paid maternity leave is available in a large number of countries including those with very low fertility rates. There is little evidence that, of itself, it has had an impact on birth rates. Germany seems to provide a clear instance of a lack of impact of paid maternity leave upon fertility. However, to the extent that it provides major financial assistance and a guarantee of return to the same job, the expectation would be that paid maternity leave should have a positive effect upon fertility. Paid maternity leave contributes to child development because it means that the baby will be in the principal care of its mother in the first months of life. It is simple and transparent and efficient in that it encourages a return to the labour force. Experience in Sweden has shown that a considerable cross-sectional impact on fertility was obtained through changing the paid maternity leave arrangements in such a way that made it beneficial to have two births relatively close together ('speed bonus'). Thus, paid maternity leave policy can influence the timing of births. On the other hand, paid maternity leave can have equity problems: it may be paid only to women who have been working for the same employer for a given length of time; it may not be paid to those who are not working; it may be contingent upon a return to work at a time that is not preferred by the parent or the level of payment may be contingent upon prior social insurance accumulation.

Paid paternity leave has an impact that is more diffuse. It engages fathers with their children, a benefit in most cases to child development, but it also goes some way towards the ideal of gender equity in relation to the impact of children upon the opportunities of men and women. Similar arguments can be made in respect of unpaid parental leave but, of course, the money is important.

An obstacle to family-friendly workplace arrangements is that they can engender resentment among those who do not have children. Workers without children can see themselves as doing more work for the same pay. They can even see themselves as directly 'covering' for the person who has children. This is especially the case for the person who comes onto the payroll to replace a woman who goes on maternity leave. Such a person is holding his or her position at the leisure of the woman on maternity leave. This is another example of why promotion of broad social understanding of the importance of supporting those with children must be part of a country's policy. 


\section{Employment Policy for Young People}

In general, fertility rates tend to be lower in countries that have recent experience of unemployment among young people or recent experience of the introduction of short-term work contracts. Delay of the first birth is undoubtedly highly associated with risk aversion on the part of young people induced by the competitive nature of the labour market in the new economy (McDonald 2006). Research has shown that young people who have been successful in obtaining secure employment, all else being equal, are more likely to embark upon family formation at an earlier age than those who have not been successful (Kravdal 1994). When risk aversion is an important part of the equation, perceptions become more important than reality. In South Korea, for example, the Asian financial crisis led to higher unemployment and restructuring of job contracts for many young workers, but by no means the majority. Even though unemployment fell relatively rapidly after the crisis, the perception has remained that the labour market is risky and precarious. With the persistence of this perception, fertility continued to plummet.

In theory, a change in employment policy for young people that reduced these perceptions of risk could have an immediate cross-sectional impact upon fertility. Longer security of job tenure is clearly the leading area for reform, especially the elimination of very short-term contracts. This would be likely to have broad political support, but is also likely to be opposed by private employers where such practices are common. Again, governments can lead the way as has been the case in some countries in relation to family-friendly workplace arrangements.

Needless to say, a strong economy with low unemployment and good prospects for young people will be a stimulus to fertility and to earlier family formation. In general, however, these will be the aims of any government and would not be seen as being specific pronatalist policies.

\section{Public Education Campaigns}

Campaigns directed at young women to breed in the interests of the nation are clearly counter-productive. On the other hand, education relating to understanding conception and the risks of waiting too long if you want to have children may be valuable. In Australia, there has been a great deal of public discussion in newspapers and women's magazines in relation to the risks of 'waiting too long'. This discussion seems to have served as a public education program and may possibly have had a cross-sectional impact on fertility. Fertility rates have risen more sharply in recent years at all ages in the thirties.

Of less obvious efficacy may be campaigns in support of family life or allaying unwarranted fears about the future, but these would have to be very sensitive in their application. Education campaigns do not cost very much but 
there may be political objection to governments trying to influence values at this personal level. Campaigns of this type are often seen as part of a conservative agenda and tend to be rejected by the left.

\section{Broader Societal Arrangements}

There is a wide array of broader social changes that can affect fertility rates. Lutz and Skirbekk (2005) have suggested that policy should effect an earlier completion of full-time education so that the post-education pathway to family formation begins at an earlier age. Several countries in East Asia have considered policies that will increase the number of marriages. Access of parents with children to leisure and recreation facilities and the provision of child-friendly environments have also been suggested.

\section{Conclusion}

Countries with very low fertility rates (under 1.5) have an interest in policies that produce a large cross-sectional effect upon the birth rate. Those with fertility rates in the safety zone between 1.5 and 2.0 births per woman have an interest in sustaining the existing level of fertility. To do this, logically, policy should affect the decision making of as many potential mothers as possible at the same time. Policies that may do this are the introduction of a large cash payment for each new birth, a Swedish-style speed bonus attached to paid maternity leave or an education campaign concerning the risks involved for women who delay having children when their intention is to have children. A higher level of security regarding future access to quality child care at an affordable price or a shift to greater security of employment for all workers would also be likely to achieve an immediate boost in births but may be more difficult to implement in a short time frame. All these policies satisfy most of the principles of good policy approaches as described above. However, they need to be subjected also to the principle of endurance.

By the endurance principle, the policy must change society once and for all without the possibility of slipping back to a new era of very low fertility. The policies described in the previous paragraph all tend to be enduring, however, any one of these policies on its own does not constitute a change in the nature of society, a radical shift towards the support of those who have children. This can only be achieved through a comprehensive approach to policy. A comprehensive approach would simultaneously address the financial impact of having children, child care and early childhood education and workplace arrangements, the tripod of good family support policy. Depending upon the country, it may also involve 
housing assistance for young couples, a higher level of security of tenure of jobs for young people and changes in values regarding the timing of the first birth.

\section{References}

Adkins, D. 2003. "The role of institutional context in European regional fertility patterns." Paper presented at the 2003 Annual Meeting of the Population Association of America, Boston.

Commission of the European Communities. 2005. Confronting demographic change: $a$ new solidarity between the generations. (Green Paper). Brussels, European Commission.

D'Addio, A. and M. d'Ercole. 2005. "Trends and Determinants of Fertility Rates in OECD Countries: The Role of Policies." OECD Social, Employment and Migration Working Papers No. 27. Paris, OECD.

Demeny, P. 2003. "Population Policy." Entry in P. Demeny and G. McNicoll (eds.) Encyclopedia of Population, New York: Thomson Gale.

Gauthier, A. and Hatzius, J. 1997. "Family benefits and fertility: an econometric analysis." Population Studies 51(3): 295-306.

Howard, J. 2006. Transcript of the Prime Minister, The Honourable John Howard's Address to the Menzies Research Centre, 18 April 2006. «http://www.pm.gov.au/news/speeches/speech1885.html»

Kravdal, Ø. 1994. "The importance of economic activity, economic potential and economic resources for the timing of the first birth in Norway." Population Studies 48(2): 249-267.

Lutz, W. and V. Skirbekk. 2005. "Policies addressing the tempo effect in low-fertility countries." Population and Development Review 31(4): 699-720.

Lutz, W., B. O’Neill, and S. Scherbov. 2003. "Europe's population at a turning point." Science 299(28) March, pp. 1991-92.

Mazumdar, P. 2003. "Eugenics." Entry in P. Demeny and G. McNicoll (eds.) Encyclopedia of Population, New York: Thomson Gale.

McDonald, P. 1990. "The costs of children; a review of methods and results." Family Matters 27, Melbourne, Australian Institute of Family Studies.

McDonald, P. 2006. "Low fertility and the state; the efficacy of policy." Population and Development Review 32(3): 401-510.

McDonald, P. and R. Kippen. 1999. Population Futures for Australia: The Policy Alternatives, Parliamentary Library Seminar Series, Research Paper 5, Canberra, Australian Parliamentary Library.

McDonald, P. and R. Kippen. 2001. "Labour supply prospects in 16 developed countries, 2000-2050." Population and Development Review 27(1): 1-32.

McDonald, P. and J. Temple. 2006. Immigration and the Supply of Complex Problem Solvers in the Australian Economy. Canberra, Australian Government, Department of Immigration and Multicultural Affairs.

Milligan, K. 2002. "Quebec's baby bonus: can public policy raise fertility?" Backgrounder, C.D. Howe Institute, January 2002.

Ogawa, N., M. Kondo, and R. Matsukura. 2005. “Japan's transition from the demographic bonus to the demographic onus." Asian Population Studies 1(2): 207-226. 
PDR. 2006. "Vladimir Putin on raising Russia's birth rate". Population and Development Review 32(2): 385-389.

Skirbekk, V. 2004. "Age and individual productivity: a literature survey." Vienna Yearbook of Population Research 2004: 133-154.

Teitelbaum, M. and J. Winter. 1985. The Fear of Population Decline. San Diego: Academic Press.

United Nations. 2000. Replacement Migration: Is It a Solution to Declining and Ageing Populations? ESA/P/WP.160. New York, Population Division, United Nations.

van Peer, C. 2002. "Desired and achieved fertility." In: E. Klijzing and M. Corijn (eds.) Dynamics of Fertility and Partnership in Europe: Insights and Lessons from Comparative Research. Volume II. New York and Geneva: United Nations, pp. 117142. 